\title{
Mathematical Knowledge of Non-mathematics Students and Their Beliefs about Mathematics
}

\author{
Ljerka Jukic Matic \\ Department of Mathematics, Josip Juraj Strossmayer University of Osijek, Osijek, Croatia
}

\begin{abstract}
Mathematics is tightly interwoven with science and engineering, where it has numerous applications. In the educational context, there is an ongoing debate who should teach mathematics to non-mathematicians and how this mathematics should be taught. The knowledge gained in mathematics course is used in another course (mathematics, science or engineering), hence students should retain core concepts some time after learning. Beliefs that students have about mathematics significantly influence on their learning, and consequently on the retained knowledge. We investigated retained calculus knowledge and beliefs about mathematics in two groups of first year students coming from the science and engineering study programs. The results showed that both groups of students showed better procedural knowledge than conceptual. Also they showed positive beliefs about mathematics in their study program, but were not certain where this knowledge will be used later. However they differed in the perception of mathematics as being exciting discipline. The educational implications of these findings are also discussed.
\end{abstract}

Keywords: Calculus, Knowledge, Retention, Beliefs

\section{INTRODUCTION}

Problem of communication between professional mathematicians and students who study in non-mathematics study programmes often represents an obstacle in comprehending taught subject matter (Maull \& Berry, 2000). In non-mathematics study programs like engineering, there is an ongoing debate who should teach mathematics to non-mathematicians and how this mathematics should be taught. Some academics advocate that the teaching of mathematics must be in the hands of professional mathematicians, while others argue that the engineering departments should integrate mathematics into the engineering courses; some academics support rigor/formality approach for teaching mathematics, while others argue against it (Flegg et al., 2012). Similar problems concerning mathematics can be found in the science study programs. In the educational context, the relationship between mathematics and sciences is a source of debate that lasts more than several decades (Matthews et al., 2009). In the secondary education in Croatia, and in many other countries as well, these disciplines are portrayed and taught as disciplines distant from each other, even when the same teacher teaches them. This mathematics-science debate has moved from the secondary education into the higher education with a bit different form and language, focusing on specific competences that students should gain in the undergraduate science curriculum (Orton \& Roper, 2000). 
Mathematics does not serve only to mathematicians as a basis of mathematical modeling and a problem solving tool. It is tightly interwoven with science and engineering, where it has numerous applications (Helfgott, 2004). Therefore, to be able to re-design the teaching of mathematics to non-mathematics students, we as the teachers of mathematics should be aware of the relevance of mathematics in engineering and science study programs. On the other hand, we should be conscious about students' attitudes and beliefs about mathematics and we should get an insight into the knowledge that students retain after the teaching and learning. The knowledge gained in mathematics courses e.g. calculus, is used in another course - science, engineering or mathematics, and the teachers in those courses frequently complain on students' mathematical knowledge (Czocher et al., 2013). Taking into consideration the aforementioned discussion, we designed the study that investigated retained calculus knowledge and beliefs about mathematics in two groups of students coming from the science and engineering study programs.

\section{Theoretical Background}

\section{Procedural and conceptual knowledge}

Various definitions of knowledge appeared during last decades, but we have chosen categorization into procedural and conceptual knowledge as the most appropriate one for our research. Conceptual knowledge is the type of knowledge which is rich in relationships and provides an understanding of the principles and relations between pieces of knowledge in a certain domain while procedural knowledge is what enables us to quickly and efficiently solve problems. Procedural knowledge can be learnt with or without meaning and consists of a sequence of actions (Hiebert \& Lefevre, 1986). Haapasalo and Kadijevich (2000) gave another definition of procedural and conceptual knowledge which highlights their dynamic nature; procedural knowledge is dynamic utilization of algorithms or procedures within representation form, and conceptual knowledge denotes ability to browse through a network consisting of concepts, rules, algorithms, procedures and even solved problems in various representation forms. Star (2005) argues that using the terms conceptual and procedural knowledge confuses knowledge types with knowledge quality. He offers new definitions of conceptual and procedural knowledge. Conceptual knowledge could be better understood in terms of "knowledge of concepts and principles" and procedural knowledge in terms of "knowledge of procedures". Star's re-definition of conceptual and procedural knowledge makes possible to consider also deep well-connected procedural knowledge, and superficial and weakly connected conceptual knowledge. In this paper we have adopted Star's definition to be able to better characterize both types of knowledge.

\section{Retention of knowledge}

The retention of learnt subject matter is one of the major goals of the educational system that relies on the assumption that learnt material will be remembered to some degree some time after the learning, and this enables further courses to build upon this material. There is not a unique agreed-upon measure of knowledge retention, but in educational contexts, most commonly used are cued recall and recognition (Custers, 2010). Cued recall is based on open-end question, while recognition is examined through true-false question. Multiple choice questions combine recall and recognition (Arzi et al., 1986). There is not necessarily a dichotomy between retention and non-retention, but there is a state between the two of them. The main purpose of the educational system is not that a student immediately remembers an answer when asked, but to reconstruct the knowledge with little effort. If a student after a hint fully remembers the knowledge that is being asked for, this can be regarded just as good as retention. This argument is in line with a discussion of Karsenty (2003), where it is argued that recalling something is a reconstruction process that yields to 
an altered version. Recalling is not a process of reproduction, where details are coded in memory and they re-appear as so-called 'copies'. On the other hand, the retention of knowledge can be defined as the extent to which someone can successfully access and use the information from the long-term memory (Sousa, 2000). We argue that this definition is also in line with previous discussion about measures of retention.

Several studies investigated the effect of teaching style on the retention of mathematical knowledge days, months and years after instructions, obtaining different results. In some cases students from student-centered courses retained conceptual knowledge better and those form teacher-centered courses retained procedural knowledge better (e.g. Garner \& Garner, 2001; Jukić \& Dahl, 2011). In some cases students from student centered-courses retained better conceptual than procedural knowledge, but they had procedural knowledge at equal level as those students coming from teacher-centered courses (Allen et al., 2005). On the other hand, Kennedy \& Schumacher (2008) found no statistically significant differences when comparing the performance of students in teacher and student-centered calculus course.

Engelbrecht et al. (2007) investigated engineering students' knowledge in basic techniques from a first-year calculus course. Comparing their results from the pre-test and the post-test given two years after the instructions, they found a significant decline in student's performance. Another reason for being interested in the long term retention of the students' knowledge is that it is not always linked with the actual course grade. In Jukic \& Dahl, (2010), the calculus teaching was investigated at one Croatian and Danish university in terms of the students' retention of key procedural and conceptual concepts of derivative two months after having passed similar Calculus 1 courses, and while being taught a Calculus 2 course. The results showed that for both countries a large portion was forgotten and that the passing grades of the Calculus 1 course did not predict the results in the test two months later. In fact, often students with the lowest passing grades had the better results two months later, or there was no difference.

\section{Beliefs, attitudes and knowledge}

When describing someone's thoughts and decisions toward world around, based on his observations and experiences, we use two words, beliefs and attitudes, and many times as synonyms. Some regard an attitude as collection of beliefs while others classify a belief as one component of attitude (e.g. Goldin et al., 2009). It is generally agreed that there is no universal acceptance in mathematics education what a definition of belief is. Beliefs are highly subjective, and they change according to someone's feelings. Students' beliefs about mathematics and mathematics learning have been a commonly shared interest among mathematics educators in last few decades. Furinghetti \& Pehkonen (2002) described beliefs as individual's subjective knowledge and gave characterization on the view of mathematics as a mixture of knowledge, beliefs, conceptions, attitudes, and feelings. This characterization has four main components: belief about mathematics, belief about oneself as mathematics learner and as user of mathematics, belief about mathematics teaching and belief about mathematics learning. Many times when the term attitude is used, it includes beliefs about mathematics and about oneself (e.g. McLeod, 1992).

There exists strong connection between knowledge and beliefs. Several studies (e.g. Dart et al., 2000; Furinghetti \& Pehkonen, 2002; Johnston, 2001; Kember \& Wong, 2000) have shown how beliefs have a high impact on students' effective learning and use of mathematics. They shape students to become passive or active learners, who cope with taught matter with different methods. The first case is characterized by rote learning and remembering, and the second by learning with understanding.

According to Ernest (2003), many studies have shown that non-mathematics students in higher education often have negative images, beliefs and attitudes towards mathematics. If such student, e.g. engineering or science, does not see the importance of mathematics in his studies or in the future professional practice, he will not believe that mathematics is 
useful. This would lead to a decline of motivation and interest to spend time working on mathematics, and regardless of what approach to curriculum is employed, student's interest is likely to be low (Flegg et al., 2012).

\section{Research focus}

We have investigated conceptual and procedural knowledge in students belonging to the engineering and science study programs, two months after the instructions and examination have taken place. Also, we have examined students' beliefs about mathematics in general and to calculus courses taken. Our main objective was to see if there are relations between these beliefs and the retained knowledge. The research reported here should be seen as exploratory and the conclusions are of relevance to the Croatian context and to other similar university contexts.

\section{METHOD}

\section{Participants}

The participants in this study were first year non-mathematics students form one Croatian university, belonging to civil engineering (65), electrical engineering (40), chemistry (36) and food science (33) study programs. We decided to divide participants in two groups according to the nature of their study program, and hereafter they will be referred to as engineering and science students. The students were surveyed using questionnaires that were administered before the exercise lessons in a mathematics course. The questionnaires were not pre-announced, so participants were those students who came to the exercise lessons. Filling the questionnaire was voluntary so some students did not respond to all questions.

In this university, each study program has its own calculus courses. The courses contain elements of mathematical analysis to emphasize the theoretical background, not just calculus techniques. In order to obtain a passing grade, students had to pass both a written and an oral exam where the students' knowledge in formal mathematical theory is also examined. Calculus courses in each study program have common parts, thus we investigated retained knowledge in differential and integral calculus that are common for the study programs chosen for this study.

\section{Questionnaire Design}

To be able to investigate students' retention of knowledge, we designed the questionnaire with multiple choice questions. As mentioned above, multiple choice questions combine recall and recognition (Arzi et al., 1986). Several questions were similar to the questions in Jukić \& Dahl (2011), but this time option "none of the above" was not included. We had examined the teaching materials used in calculus courses, and had designed tasks that investigate core calculus knowledge. We consulted the lecturers and the teaching assistants of the courses about the relevance of the questions, formulation, and appropriateness of the options of answers.

The questions from differential calculus dealt with the formal definition of derivative (Theory) and the geometric interpretation of the derivative of a function at a given point (Slope), with differentiation of a simple rational function (Quotient) and a composite function (Composition), and solving a problem that combines several concepts from differential calculus; the slope of a tangent line as the derivative of the function $f$ at the given point and the process of differentiation (Application). The questions from integral calculus dealt with the geometric interpretation of the integral (Area) and with a primitive function of some 
function $f: R \rightarrow R$ (Antiderivative), and asked students to compute several indefinite integrals (Method and Integrals). All questions can be seen in the Appendix.

We used Star's (2005) categorization into procedural and conceptual knowledge and we have grouped the questions in these two categories. If one regards conceptual knowledge as knowledge of concepts and principles, the questions Slope, Application, Theory, Area and Antiderivative form the conceptual category. If one regards procedural knowledge as knowledge of procedures, the questions Quotient, Composition, Method and Integrals form the procedural category. The concepts procedural and conceptual are not absolute, and some questions can be placed in both categories like Application or Composition. In the case of Composition, several differentiation rules have to be connected and this can be considered as conceptual knowledge. Also, solution to the Application could be based only on recalling the method without any conceptual knowledge. In our case, the students were exposed more to the chain rule of differentiation, unlike the questions like Application.

The students were asked also to respond to some beliefs questions (see Table 3), given on a 4 -point Likert-type scale, ranging from $1=$ strongly disagree, $2=$ disagree, $3=$ agree to $4=$ strongly agree. The questions aimed at exposing their beliefs about mathematics and the application of mathematics in the rest of their studying program. The neutral option was omitted since we wanted the student to take a stand.

To compare results from engineering and science students in calculus questions, we used Fisher's exact p-value test to investigate obtained quantitative data. For small, sparse, or unbalanced data, the exact and asymptotic p-values can be quite different and may lead to opposite conclusions concerning the hypothesis of interest. The Fisher's test is, as its name states, exact, and it can therefore be used regardless of the sample characteristics. To analyze Likert items, we used non-parametric Mann-Whitney test.

\section{FINDINGS}

\section{Calculus questions}

Table 1 below shows the distribution of correct answers for all questions in the two groups of students, engineering and science. No question was answered correctly by any group. The question Application had the lowest correct answer rate in both groups. The question with the best correct answer rate differs for the engineering and science students. The engineering students answered question Quotient $(80 \%)$ the best, while the science students answered the Antiderivative the best (83\%).

Table 1. Distribution of correct answers. p-values here indicate the size of the differences among the populations

\begin{tabular}{|c|c|c|c|c|c|c|c|}
\hline \multirow[t]{2}{*}{ Type } & Topic & Question & Engineering & & Science & & Fisher's \\
\hline & & & \#/total & $\%$ & \#/total & $\%$ & $\mathrm{p}$-value \\
\hline \multirow[t]{5}{*}{ Conceptual } & Differential & Slope & $55 / 102$ & 54 & $30 / 63$ & 48 & 0.5216 \\
\hline & calculus & Application & $21 / 103$ & 20 & $13 / 65$ & 20 & 1.0000 \\
\hline & & Theory & $42 / 106$ & 40 & $30 / 65$ & 46 & 0.4281 \\
\hline & Integral calculus & Area & $77 / 105$ & 73 & $43 / 66$ & 65 & 0.3036 \\
\hline & & Antideriv. & $77 / 105$ & 73 & $54 / 65$ & 83 & 0.1888 \\
\hline \multirow[t]{2}{*}{ Procedural } & Differential & Quotient & $85 / 105$ & 81 & $51 / 69$ & 74 & 0.3484 \\
\hline & calculus & Composition & $67 / 105$ & 64 & $49 / 64$ & 76 & 0.0903 \\
\hline
\end{tabular}




$\begin{array}{ccccccc}\text { Integral calculus } & \text { Method } & 65 / 103 & 63 & 43 / 66 & 65 & 0.7454 \\ & \text { Integral a } & 32 / 103 & 31 & 50 / 65 & 77 & <0.0001 \\ & \text { Integral b } & 66 / 105 & 63 & 46 / 65 & 71 & 0.3212\end{array}$

There was a significant difference how the science and the engineering students answered only one of 10 questions at the level of 0.05 , where the science students outperformed the engineering students in the procedural question Integral $a$.

Table 2 below shows how well each of the two populations solved each of the conceptual questions compared to each of the procedural questions.

Table 2. Fisher's p-values comparing answers to the procedural and conceptual questions by population

Engineering students

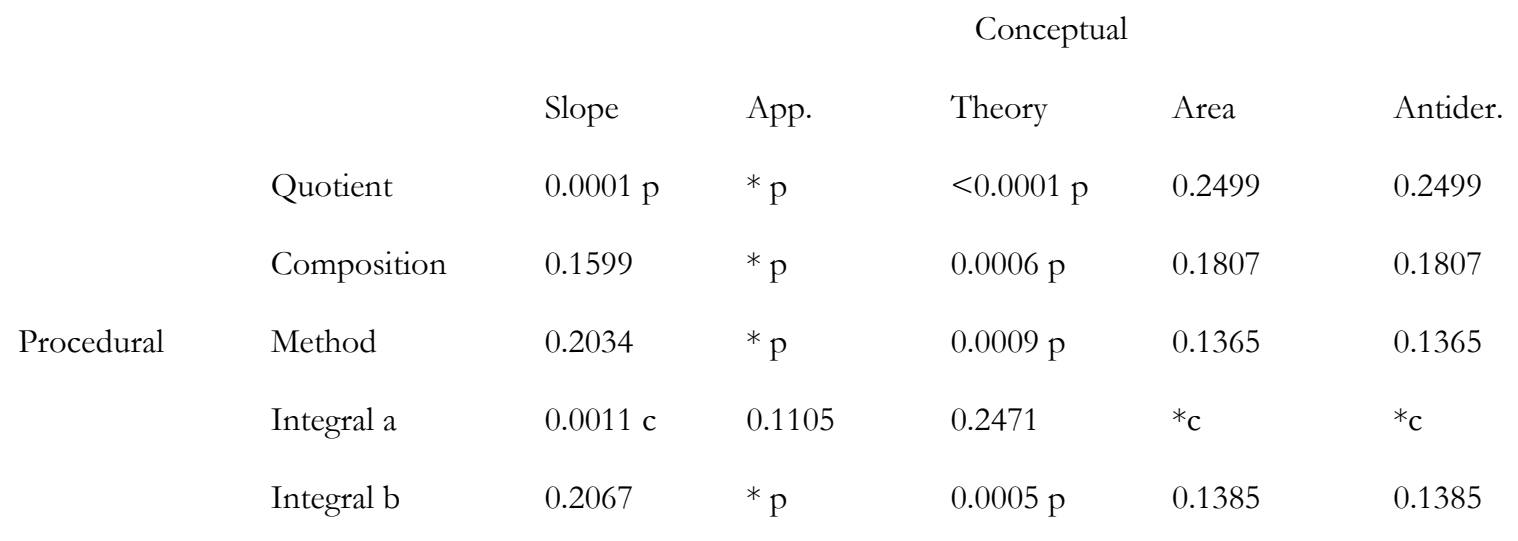

Science students

\begin{tabular}{|c|c|c|c|c|c|c|}
\hline & & \multicolumn{5}{|c|}{ Conceptual } \\
\hline & & Slope & App. & Theory & Area & Antider. \\
\hline \multirow{5}{*}{ Procedural } & Quotient & $0.0024 \mathrm{p}$ & $* \mathrm{p}$ & $0.0014 \mathrm{p}$ & 0.3494 & 0.2151 \\
\hline & Composition & $0.0010 \mathrm{p}$ & $* \mathrm{p}$ & $0.0005 \mathrm{p}$ & 0.1794 & 0.3874 \\
\hline & Method & $0.0520 \mathrm{p}$ & $* \mathrm{p}$ & $0.0352 \mathrm{p}$ & 1.0000 & $0.0277 \mathrm{c}$ \\
\hline & Integral a & $0.0009 \mathrm{p}$ & $* \mathrm{p}$ & $0.0005 \mathrm{p}$ & 0.1780 & 0.5112 \\
\hline & Integral b & $0.0015 \mathrm{p}$ & $* \mathrm{p}$ & $0.0073 \mathrm{p}$ & 0.5745 & 0.1443 \\
\hline
\end{tabular}

Note: $*$ denote $\mathrm{p}<0.0001$.The letters $\mathrm{p}$ (procedural) and c (conceptual) denotes which question had the best answer rate

The results of Table 2, and data from Table 1, show that for the engineering students there was a significantly different performance in 12 out of 25 comparisons of the two groups of questions at the level of 0.05 . Of the 12 comparisons which showed a significant difference, 9 times engineering students answered the procedural question better, and three times they answered the conceptual question better. Hence it appears that the engineering students had preference for the procedural questions. In the procedural group, the engineering students achieved better results in the differential questions than in the integral questions. In the conceptual group, their results were better for the integral questions than for the differential question.

The results of Table 2, and data from Table 1, show that for the science students there was a significantly different performance in 16 of the 25 comparisons of the two groups of questions. Of the 16 comparisons which showed a significant difference (alpha of 0.05), 15 times the procedural question was answered the best, while one time the conceptual 
question had the best answer rate. This suggests that the science students had retained better knowledge in the procedural questions than in the conceptual questions. In the conceptual group of questions, the science students achieved better results in the integral questions than in the differential questions. In the procedural group, their results had almost the same correct answer rate in the integral and differential questions.

\section{Belief Statements}

The statements from the questionnaires and the results of the students' responses are presented in Table 3. A larger proportion of the engineering students agreed with the statements 1, 2 and 3 than the proportion of science students, except for the statement 6 , where this proportion was the same. This means that significant proportion of students from both groups considered that mathematics was important in technical and natural sciences, with $93 \%$ of engineering students and $76 \%$ of science students who agreed (and strongly agreed) with this statement. Also, above $90 \%$ of students from both groups regarded that knowledge in basic mathematical disciplines was necessary for students in these sciences. Understanding mathematics behind problem was important for $87 \%$ of engineering students and $74 \%$ of science students. Although the two groups of students had very similar responses to statements 1,2 and 3 , a significant difference was found between the engineering and science students at the level of $0.05(p=0.0415, p=0.00001$ and $\mathrm{p}=0.0068$ respectively). This indicates that the engineering students have more positive beliefs about the role of mathematics in their study program.

In the statements 4,5 , and 7 , the two groups of students differed-more than half of engineering students agreed while more than half of science students disagreed (and strongly disagreed) with those statements. 54\% of engineering student considered mathematics as exciting, while $64 \%$ of science students disagreed with that. When it comes to calculus courses taken, $60 \%$ of engineering students considered that calculus courses were interesting, while $60 \%$ of science students disagreed with this statement. $51 \%$ of engineering students claimed that they saw the application of integrals in the rest of their study program, compared to $56 \%$ of science students who disagreed with it. At the level of 0.05 , a significant difference was found between the engineering and science students in statement $4(\mathrm{p}<0.00001)$ and statement $5(\mathrm{p}=0.00001)$, what confirmed that there exists notable difference between those two groups of students.

Table 3. Responses to the beliefs statements: percentages, mean, standard deviation

\begin{tabular}{|c|c|c|c|c|c|c|c|}
\hline \multirow[t]{2}{*}{ Statements: } & Groups & StDis. & Dis & Agr. & StAgr. & $\mathrm{M}$ & SD \\
\hline & & $\%$ & $\%$ & $\%$ & $\%$ & & \\
\hline 1. Everyone who studies natural and technical sciences ought to have & $\mathrm{E}$ & 1 & 4 & 45 & 50 & 3.43 & 0.63 \\
\hline knowledge of basic mathematical disciplines. & S & 1 & 9 & 51 & 39 & 3.28 & 0.65 \\
\hline \multirow[t]{2}{*}{ 2. Mathematics is a central part of technical and natural sciences. } & $\mathrm{E}$ & 1 & 6 & 58 & 35 & 3.26 & 0.63 \\
\hline & S & 4 & 20 & 59 & 17 & 2.88 & 0.72 \\
\hline 3. It is important to me not just to be able to solve a problem, but also & $\mathrm{E}$ & 2 & 11 & 51 & 36 & 3.22 & 0.70 \\
\hline to understand the mathematics behind it. & S & 4 & 22 & 47 & 27 & 2.98 & 0.80 \\
\hline 4. Mathematics is an exciting subject in general. & $\mathrm{E}$ & 10 & 36 & 40 & 14 & 2.56 & 0.85 \\
\hline
\end{tabular}




\begin{tabular}{|c|c|c|c|c|c|c|c|}
\hline & $\mathrm{S}$ & 26 & 40 & 30 & 4 & 2.14 & 0.85 \\
\hline \multirow{2}{*}{$\begin{array}{l}\text { 5. Calculus courses were interesting to me beyond the fact that I had } \\
\text { them as a part of my study program. }\end{array}$} & $\mathrm{E}$ & 9 & 31 & 45 & 15 & 2.65 & 0.84 \\
\hline & S & 20 & 40 & 35 & 5 & 2.27 & 0.84 \\
\hline \multirow[t]{2}{*}{ 6. I think derivatives have applications in the rest of my study program. } & $\mathrm{E}$ & 25 & 17 & 25 & 33 & 2.65 & 1.18 \\
\hline & S & 25 & 17 & 33 & 25 & 2.57 & 1.12 \\
\hline \multirow[t]{2}{*}{ 7. I think integrals have applications in the rest of my study program. } & $\mathrm{E}$ & 21 & 28 & 29 & 22 & 2.51 & 1.07 \\
\hline & $\mathrm{S}$ & 29 & 29 & 21 & 21 & 2.34 & 1.11 \\
\hline
\end{tabular}

Note: $\mathrm{E}=$ engineering, $\mathrm{S}=$ science, $\mathrm{M}=$ mean, $\mathrm{SD}=$ standard deviation, $\mathrm{StDis}=$ strongly disagree, Dis=disagree, Agr=agree, StAgr = strongly agree

\section{DISCUSSION AND CONCLUSIONS}

We investigated retained calculus knowledge in the engineering and science students two months after instructions and examination have taken place. Tasks, that we used, asked for core calculus knowledge and were created in collaboration with the lectures and the teaching assistants who taught students from the surveyed study programs. The results showed that the engineering students retained slightly better procedural knowledge than conceptual. Also a significant number of engineering students experienced problems with the conceptual knowledge in differential calculus, i.e. with the geometrical interpretation of derivative, its application, and the formal definition of the derivative. The science students retained far better knowledge in the procedural questions than in the conceptual questions, where many students had problems with the geometrical interpretation of both calculus concepts, derivative and integral, and with the formal definition of the derivative.

One could argue that students could have forgotten concepts investigated in this study especially if they are not used over some time. But participants in this study remained in contact with calculus concepts in next mathematics courses. Engelbrecht et al. (2007) found that there is decline in knowledge that is not used regularly, but when the knowledge is encountered along the way, the retention should be strengthened. According to Semb et al. (1999), the retained knowledge depends on the original learning, what indicates that students did not gain good level of knowledge when they were learning it. A reason for preferring procedural knowledge over conceptual could lie in the formal mathematical theory presented in the taken calculus courses. Teaching and learning mathematics in the definition-theorem-proof style is difficult for many freshmen, wherefore they seek the security of the procedural rules (Tall, 2001). Studies showed that procedural knowledge is the one that faster deteriorates with time (e.g. Allen et al., 2005). If there is no conceptual meaning, this kind of knowledge is very fragile in the long term memory and usually remembered inappropriately.

The results from the previous section showed that the engineering students saw mathematics as an important part of their study program, and considered that every person who studies in engineering study program should possess basic mathematical knowledge. They highly appreciated an understanding of mathematical concepts, not only a performance of procedure, but this was not entirely supported with results in the calculus questions. They found mathematics and calculus courses interesting, but they were divided in their belief whether calculus concepts will be used or not in the rest of their study 
program, what indicates that the relationship between mathematics and engineering was not visible to them even at the end of the first year of the their studying. The science students expressed the same beliefs as the engineering students about mathematics, basic mathematical knowledge in their study program and the understanding of mathematics in problems but with less conviction. However, more than half held a belief that mathematics in general and calculus taken were not interesting unlike the majority of engineering students. Similarly as the engineering students, the science students were not sure if mathematical concepts from calculus will have application in the rest of their study program: for differential calculus more than half participants agreed, and for integral calculus more than half disagreed. This belief indicates that students have not seen the practical application of their mathematical knowledge in the science context, meaning that the relationship between mathematics they took and the rest of their study program was not shown in the first year of their studying.

In all, both groups of students considered mathematics as a necessary part of their study program, but were uncertain where their mathematical knowledge will be used later on. Similarly, a study by Flegg et al. (2012) found that the first year engineering students believed that mathematics was a relevant part of engineering, but were not able to relate mathematics to their later engineering courses. Orton \& Roper (2000) found that the first year science students held misguided belief that mathematics was irrelevant in science.

Students should be aware of the relationship between mathematics and engineering or science early in their studies, but there is not unique approach how this should be done. Matthews et al. (2009) describe the interdisciplinary approach which combines mathematics and science, keeping the boundaries between disciplines visible. On the other hand, Flegg et al. (2012) give recommendation for mathematics in the engineering curricula where mathematics is used as a tool for dealing with real world problem. Beliefs about mathematics in general and calculus courses taken significantly differed between the science and engineering students and we argue that this should be taken into account when teaching those groups of students. Therefore, choosing the best approach certainly depends on the specific study program. We believe that mathematics courses should be adapted to the particular study program, meaning that every science and engineering study programs should have its own mathematics courses, where material would be presented through the applications in that scientific discipline, at more practical level. Such emphasis on the applications in more meaningful contexts would enable better use of mathematical knowledge in the particular discipline. This also agrees with Townend [2007, p. 204]: "...if students could see that some level of mathematical skill was needed in order to investigate realistic [...] problems, then maybe they would be more prepared to invest the necessary time and intellectual effort." We would not suggest abandoning mathematical formalism and dealing only with calculus techniques. Techniques alone do not provide deep understanding and do not show under which circumstances some concept can exist and can be used. We agree with Mahavier \& Mahavier (2008) and Sazhin (1998) that nonmathematics students should not be forced to produce $\varepsilon-\delta$ proofs, but they can be trained to state, read, interpret, and apply accurately written definitions. Therefore, the formal mathematical aspects should be kept at the reasonable level.

No matter what approach we choose, it demands significant collaboration between mathematicians and academics from different scientific disciplines. Linking mathematics to science or engineering early on should make the role of mathematics visible more than it is now in many engineering and science curricula. Sazhin (1998) points out that here should be a balance between the understanding of abstract mathematical concepts and practical examples that students can relate to, and this once again puts a focus on the connection between mathematics and other courses in particular study program. We believe this would affect on students' beliefs about meaningful application of mathematics and would induce better retention of mathematical knowledge. Leaving mathematics detached from 
engineering and science, leads to belief that science and engineering do not require mathematics to educate skillful university graduates.

\section{REFERENCES}

Allen, K., Kwon, O. N. \& Rasmussen, C. (2005). Students' retention of mathematical knowledge and skills in differential equations. School Science and Mathematics, 105(5), 227-239.

Arzi, H. J., Ben-Zvi, R., \& Ganiel, U. (1986). Forgetting versus savings: The many facets of long-term retention. Science Education, $70(2), 171-188$.

Custers, E. J. F. M. (2010). Long-term retention of basic science knowledge: a review study. Advances in Health Sciences Education, 15(1), 109-128

Czocher, J. A, Tague, J. \& Baker, G. (2012). Where does the calculus go? An investigation of how calculus ideas are used in later coursework. International Journal of Mathematical Education in Science and Technology, 10.1080/0020739X.2013.780215

Dart, B. C., Burnett, P. C., Purdie, N., BoultonLewis, G., Campbell, J., \& Smith, D. (2000). Students' conceptions of learning, the classroom environment, and approaches to learning. The Journal of Educational Research, 93(4), 262-270.

Engelbrecht, J., Harding, A., \& Preez, J. D. (2007). Long-term retention of basic mathematical knowledge and skills with engineering students. European Journal of Engineering Education, 32(6), 735-44.

Ernest, P. (2003). The Mathematical Attitudes, Beliefs and Ability of Students. In: Maths for Engineering and Science. LTSN MathsTEAM. 4-5.

Flegg, J., Mallet, D. G., \& Lupton, M. (2012). Students' perceptions of the relevance of mathematics in engineering. International Journal of Mathematical Education in Science and Technology, 43(6), pp. 717-732.

Furinghetti, F., \& Pehkonen, E. (2002). Rethinking characterizations of beliefs. In G. C. Leder, E. Pehkonen, and G. Törner (Eds.), Beliefs: A hidden variable in mathematics education? (pp. 39-57). Dordrecht: Kluwer Academic Publishers.

Garner, B. \& Garner, L. (2001). Retention of concepts and skills in traditional and reformed applied calculus. Mathematics Education Research Journal, 13(3), 165-184.

Goldin, G., Rösken, B., \& Törner, G. (2009). Beliefs - no longer a hidden variable in mathematical teaching and learning processes. In J. Maaß \& W. Schlöglmann
(Eds.), Beliefs and Attitudes in Mathematics Education: New Research Results (pp. 9-28). Rotterdam: Sense Publisher.

Haapasalo, L., \& Kadijevich, D. (2000). Two types of mathematical knowledge and their relation. Journal für Mathematik-Didaktik, 21(2), 139-157.

Helfgott, M. (2004). Five guidelines in the teaching of first-year calculus. Proceedings of the 10th International Congress of Mathematical Education, Copenhagen, Denmark

Hiebert, J., \& Lefevre, P. (1986). Conceptual and procedural knowledge in mathematics: An introductory analysis. In J. Hiebert (Ed.), Conceptual and Procedural Knowledge: The Case of Mathematics, Lawrence Erlbaum Associates, Hillsdale, NJ, 1-27.

Johnston, C. (2001). Student perceptions of learning in first year in an economics and commerce faculty. Higher Education Research and Development, 20(2), 169-184.

Jukić, Lj., \& Dahl, B. (2010). The retention of key derivative concepts by university students on calculus courses at a Croatian and Danish university, Proc. 34th Conf. of the Int. Group for the Psychology of Mathematics

Education, Brasil, Belo Horizonte: PME

Jukić, Lj., \& Dahl, B. (2011). What Affects Retention of Core Calculus Concepts Among University Students? A Study of Different Teaching Approaches in Croatia and Denmark, Proceedings of 7 thCongress of the European Society for Research in Mathematics Education (CERME), Rzeszow, Poland Karsenty R. (2003). What adults remember from their high school mathematics? The case of linear functions. Educational Studies in Mathematics, 51, 117-144.

Kember, D., \& Wong, A. (2000). Implications for evaluation from a study of students' perceptions of good and poor teaching. Higher Education, 40(1), 69-97.

Krutetskii, V. A. (1976). The Psychology of Mathematical Abilities in Schoolchildren, Chicago: The University of Chicago Press.

Mahavier, William S., \& Mahavier, W. T. (2008). Calculus: The Importance of Precise Notation. PRIMUS, 18(4), 349-360.

Matthews, K. E., Adams, P., \& Goos, M. (2009). Putting it into perspective: Mathematics in the undergraduate science curriculum. 
International Journal of Mathematics Education in Science and Technology, 4O(7), 891-902

Maull, W., \& Berry, J. (2000). A questionnaire to elicit concept images of engineering students. International Journal of Mathematical Education in Science and Technology, 31(6), 899-917.

McLeod, D. B. (1992). Research on affect in mathematics education: A reconceptualization. In D.A.Grouws (Ed.), Handbook of Research on mathematics teaching and learning, New York Macmillan, 575-596

Orton, A.; \& Roper, T. (2000). Science and Mathematics: A Relationship in Need of Counselling?, Studies in Science Education. 35, 123-154.

Sazhin, S. S. (1998) Teaching Mathematics to Engineering Students. International Journal of Engineering Education, 14(2), 145-152

Schumacher, P. \& Kennedy, K.T. (2008). Lessons $\begin{array}{llr}\text { Learned } & \text { Concerning } & \text { a } \\ \text { Student Centered Teaching } & \text { Style by } \\ \text { University Mathematics } & \text { Professors } \\ \text { from Secondary School } & \text { Educators. } \\ \text { Education, 129(1), 102-109. } & \end{array}$
Semb, G. B., Ellis, J. A., \& Araujo, J. (1993). Long-term memory for knowledge learned in school. Journal of Educational Psychology, 85(2), 305-316.

Sousa, D. A. (2000), How the Brain Learns, 2nd edition, Corwin Press: Thousand Oaks, CA.

Star, J. R. (2005). Re-conceptualizing procedural knowledge. Journal for Research in Mathematics Education, 36(5), 127-155.

Tall, D. (2001). Cognitive Development in Advanced Mathematics Using Technology. Mathematics Education Research Journal, 12(3), 196--218.

Townend, M. S. (2001). Integrating Case Studies in Engineering Mathematics: A response to SARTOR 3. Teaching in Higher Education, 6(2), 203-215.

\section{$\diamond \diamond \diamond$}

\section{Citation Suggestions :}

APA : Matic, L. J. (2014). Mathematical knowledge of non-mathematics students and their beliefs about mathematics. Mathematics Education, 9(1), 13-24.

\section{APPENDIX}

\section{Derivatives questions surveyed with given options for answers}

1. Question Slope: What is the geometric interpretation of the derivative of the function $f: R \rightarrow R$ at the point $x_{0}$ ? Offered answers: A: maximum/minimum of the function $f$ at $x_{0}$; $\mathrm{B}$ : slope of tangent line to the curve $y=f(x)$ at $x_{0}$; C: continuity of the function $f$ in the given point;

2. Question Quotient: Differentiate the function $f(x)=\frac{x^{2}+2}{x^{3}}$. Offered answers: A: $\frac{x^{3}(2 x)-\left(x^{2}+2\right)\left(3 x^{2}\right)}{\left(x^{3}\right)^{2}} ; \mathrm{B}: \frac{x^{3}(2 x)-\left(x^{2}+2\right)\left(3 x^{2}\right)}{x^{3}} ; \mathrm{C}: \frac{x^{3}(2 x)-x^{2}\left(3 x^{2}\right)}{\left(x^{3}\right)^{2}}$.

3. Question Composition: Differentiate the function $f(x)=\sin ^{2} 6 x$. Offered answers: A: $2 \sin (6 x) ; B: 12 \sin (6 x) ; C: 12 \sin (6 x) \cos (6 x)$.

4. Question Application: Calculate the slope of the tangent line to the curve $y=(3 x)^{2}$ at the point $x=1$. Offered answers: A: 9; B: 18; C: 6 .

5. Question Theory: Which of the following holds:

A. A derivative of the function $f: R \rightarrow R$ at the point $\mathrm{x}_{0}$ is $\lim _{x \rightarrow x_{0}} \frac{f(x)}{x}$, if this limit exists. 
B. A derivative of the function $f: R \rightarrow R$ at the point $\mathrm{x}_{0}$ is $\lim _{x \rightarrow x_{0}} \frac{f\left(x-x_{0}\right)}{x-x_{0}}$, if this limit exists.

C. A derivative of the function $f: R \rightarrow R$ at the point $\mathrm{x} 0$ is $\lim _{x \rightarrow x_{0}} \frac{f(x)-f\left(x_{0}\right)}{x-x_{0}}$, if this limit exists..

\section{Integral questions surveyed with given options for answers}

1. Question Area: Let $f$ be bounded function and $f(x) \geq 0$, for $\mathrm{x} \in[a, b]$. What is the geometric interpretation of the definite integral $\int_{b}^{a} f(x) d x$ ? Offered answers: A: The area between the curve $y=f(x)$ and the $x$-axis for $x$ between $a$ and $b$; B: The arc length of the curve $y=f(x)$ on the interval $[a, b]$; C: continuity of the function $f$ on interval $[a, b]$; D: volume of solid of revolution on interval $[a, b]$ around $x$-axis

2. Question Antiderivative: What is an antiderivative of a function $f$ ? Offered answers: A: $\int f^{\prime}(x) \mathrm{d} x$; B: every function $F$ such that $F^{\prime}(x)=f(x)$ holds; C: the set of elementary functions; D: every function in Taylor series .

3. Question Method: Which method is the most appropriate for computing the integral $\int x e^{x} d x$ ? Offered answers: A: substitution $t=e^{x}$; B: integration by parts; C: trigonometric substitution; D: direct integration.

4. Question Basic integrals:
a. $\quad \int \frac{d x}{1+x^{2}}=$ ? Offered answers: A: $\ln \left(1+x^{2}\right)+C ;$ B: $\arctan x+C$.
b. $\quad \int \frac{d x}{x^{3}}=$ ? Offered answers: A: $-\frac{1}{2} x^{-2}+C ; \mathrm{B}: \ln \left(x^{3}\right)+C$. 